\title{
Limites e possibilidades do Atendimento Educacional Especializado numa escola de tempo integral
}

\author{
Marcos Elias Sala* \\ Kênia Santos Moreno** \\ Amanda Aparecida Pereira Duarte ${ }^{* * *}$
}

\begin{abstract}
Resumo:
O presente trabalho apresenta uma discussão a respeito da organização do AEE (Atendimento Educacional Especializado) num colégio de aplicação organizado em tempo integral, percebendo-se diversas potencialidades e limitações, que precisam ser discutidas e amadurecidas entre toda a comunidade escolar. Paralelamente, é preciso produzir conhecimento para munir o Poder Legislativo de elementos que possam contribuir na proposição de leis que favoreçam os estudantes PAEE (Público-Alvo da Educação Especial) de fato, especialmente quando se trata de crianças com necessidades especiais, que ficam durante boa parte do dia no ambiente escolar. A metodologia adotada foi a observação participante, na qual os atores/autores estão envolvidos diretamente na problemática apresentada. À guisa de conclusão, considera-se que o país inteiro ainda está num processo inicial de discussão para construção, implementação e consolidação do AEE nas escolas, apesar da relativa antiguidade da obrigatoriedade legal da oferta dessa modalidade educacional.
\end{abstract}

\section{Palavras-chave:}

Atendimento Educacional Especializado. Tempo integral. Comunidade escolar.

\begin{abstract}
:
This work presents a discussion about the organization of SEA (Specialized Educational Attendance) work in a Laboratory School organized full time, realizing several potentials and limitations, which need to be discussed and matured among the entire school community. At the same time, it is necessary to produce knowledge to provide the Legislative Branch with elements that can contribute to the
\end{abstract}

\footnotetext{
* Graduado em Geografia pela PUC/MG, mestre em Geografia pela UFMG e doutor em Geografia pela UNESP Rio Claro. Professor de Geografia e vice-diretor do Centro Pedagógico (CP/UFMG). E-mail: marcossala@geo.igc.ufmg.br. ORCID iD: https://orcid.org/0000-0002-9943-0224.

**Licenciada em Pedagogia pela Universidade Castelo Branco, especialista em Educação Especial e Inclusiva pela UNIJALES. Professora substituta de Educação Especial do Centro Pedagógico (CP/UFMG). E-mail: kenia.aee.ufmg@gmail.com. ORCID iD: https://orcid.org/0000-0002-6787-0110.

***Licenciada em Pedagogia pela UNOPAR e em Educação Especial pela UNISSANTA, especialista em Psicopedagogia pela UNOPAR. Professora substituta de Educação Especial do Centro Pedagógico (CP/UFMG).

E-mail: amandaduartes@yahoo.com.br. ORCID iD: https://orcid.org/0000-0002-6446-7908.
} 
proposal of laws that favor de facto SEND (Special Educational Needs and Disabilities) students, especially when it comes to children with special needs, who spend most of the day in the school environment. The methodology adopted was the Participant Observation, in which the actors/authors are directly involved in the problem presented. As a conclusion, it is considered that Brazil is still in an initial process of discussion for the construction, implementation and consolidation of SEA in schools, despite the Brazilian's relative antiquity of the legal obligation to offer this educational modality.

\section{Keywords:}

Specialized Educational Attendance. Full-time school. School community.

\section{Introdução}

O princípio fundamental da educação inclusiva é que todas as crianças, da melhor maneira possível, possam aprender juntas, a partir de práticas e procedimentos pedagógicos que possibilitem a aprendizagem simultânea para as diferentes realidades cognitivas e comportamentais (UNESCO, 1998). Apesar de as temáticas de educação especial e inclusiva estarem ocupando a pauta de estudos nos países mais desenvolvidos economicamente desde meados do século XIX, apenas nos últimos 10 anos é possível observar ações efetivas na educação brasileira que versem sobre esse assunto, em decorrência da elaboração e aperfeiçoamento de leis específicas, bem como decisões judiciais que obrigaram algumas escolas a iniciarem o processo de inclusão, mesmo sem haver a infraestrutura adequada e outras condições consideradas mínimas.

Com isso, apenas mais recentemente alguns Colégios de Aplicação (CAps) iniciaram o processo de inclusão. Apesar de ainda haver desarticulação das ações dos CAps, devido ao incipiente processo em curso, diversos estudos e ações vêm sendo realizados. A partir da urgência em se iniciar a inclusão nas escolas, acrescidos da falta de estudos mais sistemáticos e de infraestrutura adequada, averiguou-se a partir de conversas com alguns diretores escolares, que os CAps que já iniciaram este processo até o momento vêm trabalhando na perspectiva do "cada caso é um caso", não havendo sistematização ou uniformização de procedimentos e atitudes ante aos diferentes desafios que os estudantes Público-Alvo da Educação Especial (PAEE) apresentam. Em outras palavras, cada CAp demanda infraestrutura, profissionais e ações específicas.

Até a publicação do presente artigo, dentre os 17 CAps, o Centro Pedagógico (CP) da UFMG era o único que possuía os horários organizados no sistema de tempo integral. Nesse sentido, os desafios de implementação e manutenção de uma educação inclusiva de qualidade são específicos, pois há diversas variáveis que só podem ser observadas em escolas de tempo integral. Estudos que tratam sobre a existência e funcionamento do Atendimento Educacional Especializado (AEE) em escolas de tempo integral são praticamente inexistentes, sendo este um campo fértil para pesquisas. Associa-se a isso o fato de as leis de inclusão elaboradas até o momento desconsiderarem as particularidades das escolas de tempo integral, mesmo havendo previsão legal para a expansão e consolidação dessa modalidade de escolas pelo país (BRASIL, 2014).

Portanto, o presente estudo tem como objetivo identificar as principais potencialidades, limitações e desafios da implementação e manutenção da educação inclusiva numa escola de tempo integral, bem como realizar breves análises sobre estes elementos principais. Apesar da inevitável superficialidade de algumas reflexões e análises presentes neste texto, devido ao pequeno espaço para a adequada menção e desenvolvimento das ideias, a justificativa para a elaboração e publicação deste trabalho é o fornecimento de elementos que visem dar um panorama geral de como a Educação Especial (EE) e o Atendimento Educacional Especializado (AEE) vêm se desenvolvendo num CAp de tempo integral, bem como estimular novos estudos sobre essa temática, no âmbito dos CAps ou mesmo de outras modalidades de instituições de ensino. Usou-se a pesquisa participante como metodologia, pois os autores são alguns dos principais envolvidos no desenvolvimento da Educação Especial no CP/UFMG. Os resultados indicam que, por se 
tratar de um assunto ainda incipiente, com apenas os primeiros passos sendo dados em direção a uma mudança estrutural na forma como o processo educacional vinha sendo conduzido, há diversas potencialidades que podem ser observadas, mas há também diversas limitações e desafios, especialmente no que se refere às condições de trabalho dos docentes, servidores técnico-administrativos, infraestrutura oferecida pelo governo e suporte legal para o adequado desenvolvimento dos trabalhos. O texto se encerra valorizando aquilo que foi alcançado até o momento, mas indicando a necessidade de continuidade dos estudos, aperfeiçoamento das práticas que têm alcançado sucesso e correções de rotas, bem como a necessidade de lutar por melhores condições estruturais.

\section{Metodologia}

A metodologia adotada é a pesquisa participante, que conforme Grossi (1981, p. 43 apud DEMO, 1982, p. 86), “é um processo de pesquisa no qual a comunidade participa na análise de sua própria realidade, com vistas a promover uma transformação social em benefício dos participantes que são oprimidos”. Assim sendo, a presente reflexão, além de buscar aumentar o entendimento e conhecimento da situação vivida, busca contribuir no aperfeiçoamento das práticas adotadas que vêm dando certo, bem como na mudança daquilo que se vê como necessário. Portanto, a coletividade das ações é o que pode fazer com que haja transformação. No caso específico deste trabalho, o vice-diretor do CP elaborou esta reflexão em parceria com as duas atuais professoras substitutas de Educação Especial da instituição, a partir das experiências e práticas adotadas no cotidiano da escola, e também no intuito de delimitar a situação atual das políticas inclusivas internas adotadas, para servir como referência para o desenvolvimento de futuras ações.

\section{Princípios gerais da educação especial e o tempo integral}

Para implementação e desenvolvimento de ações inclusivas nos CAps, é necessário, em primeiro lugar, que haja embasamento legal que possa alicerçar todos os procedimentos técnico-administrativos, bem como a aquisição e adaptação de toda estrutura que forem necessárias ao bom andamento dos trabalhos. Para isso, as leis nacionais que regem a inclusão devem ser as referências a serem usadas pelos CAps, mesmo que em alguns momentos os embasamentos legais não estejam de acordo com as recentes evoluções científicas naquele campo de pesquisa.

Nesse sentido, a Educação Especial (EE), conforme Brasil (2008, p. 1), é definida como:

[...] uma modalidade de ensino que perpassa todos os níveis, etapas e modalidades, realiza o atendimento educacional especializado, disponibiliza os recursos e serviços e orienta quanto a sua utilização no processo de ensino e aprendizagem nas turmas comuns do ensino regular.

A EE, portanto, tem como princípio a articulação indissociada de todos os níveis, modalidades e práticas de ensino, em todos os anos escolares e diante de quaisquer deficiências, independente do nível de comprometimento cognitivo que cada um apresenta. Já o AEE, mencionado no trecho, é uma parte da EE, cuja função é

[...] identificar, elaborar e organizar recursos pedagógicos e de acessibilidade que eliminem as barreiras para a plena participação dos alunos, considerando suas necessidades específicas. Esse atendimento complementa e/ou suplementa a formação dos alunos com vistas à autonomia e independência na escola e fora dela. (BRASIL, 2008, p. 1). 
O AEE, portanto, não deve se limitar aos conteúdos escolares, mas deve prover ao estudante com deficiência todas as condições necessárias para a inclusão em todas as esferas da vida em sociedade.

O Decreto no 7611/11, que dispõe sobre a Educação Especial e o AEE, define-os como:

[...] o conjunto de atividades, recursos de acessibilidade e pedagógicos organizados institucional e continuamente, prestado das seguintes formas:

I - complementar à formação dos estudantes com deficiência, transtornos globais do desenvolvimento, como apoio permanente e limitado no tempo e na frequência dos estudantes às salas de recursos multifuncionais; ou

II - suplementar à formação de estudantes com altas habilidades ou superdotação.

[...] O Poder Público estimulará o acesso ao atendimento educacional especializado de forma complementar ou suplementar ao ensino regular [...]. (BRASIL, 2011).

Portanto, dentro das diversas ações de ordem didática, pedagógica, estrutural e administrativa da Educação Especial, o AEE constitui-se como uma parte de todo o processo de inclusão. Considerando a natureza do trabalho de inclusão nas escolas, avalia-se que ele não deve ser realizado exclusivamente por professores especialistas nessa temática, mas por todos os envolvidos no processo de educação, seja direta ou indiretamente. Nesse sentido, seria contraditório um processo de "inclusão" ocorrer de forma excludente, ou seja, sem envolvimento total e irrestrito de todos os atores envolvidos no processo educacional. Sendo assim, não se pode cair na armadilha de deixar a condução das ações inclusivas nas escolas a cargo de setores ou departamentos de inclusão, mas deve haver envolvimento pleno de todos os atores envolvidos, mesmo que não sejam especialistas ou estudiosos do assunto (DE BOER; PIJL; MINNAERT, 2011).

Para viabilizar a inclusão na escola, seja no chão da sala de aula ou fora dele, a metodologia de ensino pode ser colaborativa, que é quando o professor de AEE planeja e executa ações didático-pedagógicas em conjunto com o professor especialista (co-docência), ou itinerante, que é quando o ensino ocorre na chamada sala de recursos, cujo principal propósito é prover as condições de participação dos estudantes PAEE na sala regular, de acordo com suas necessidades individuais (DAVID; CAPELLINI, 2014). Vale ressaltar que o ensino na sala de recursos não deve ser visto como reforço escolar.

Com relação às salas de aula, é necessário que elas tenham a natureza inclusiva, ou seja, que todas as condições estruturais, didáticas e pedagógicas sejam oferecidas, para que a aprendizagem ocorra em condições equânimes. Para isso, considera-se que os principais tipos de salas de aula existentes são: a) classe regular/integradora, na qual os estudantes PAEE podem ter auxílio de um monitor/tutor em sala; b) salas mainstreaming, na qual os estudantes PAEE recebem atendimento especializado em sala especializada em parte do dia/semana; c) salas inclusivas, onde o estudante recebe atendimento individualizado, sem se retirar da sala para AEE; d) salas de educação especial, onde estudantes com distúrbios semelhantes são colocados numa mesma sala; e) programas especializados externos à escola, que são desenvolvidos por entidades especializadas em diferentes distúrbios, que desenvolvem habilidades muito específicas, com infraestrutura própria (HORNBY, 2015).

Sendo assim, a sala de recursos, ou sala de AEE, está contemplada na modalidade conhecida como mainstreaming, que é considerada na literatura internacional como a sala convencional para o desenvolvimento de práticas didático-pedagógicas inclusivas (HORNBY, 2015). A adoção ou não das salas mainstreaming pelas escolas não quer dizer que seja a única possibilidade de se realizar o trabalho de inclusão, mas vem sendo considerada como uma das alternativas mais eficazes ao desenvolvimento do processo inclusivo.

O CP vem diversificando os atendimentos nas perspectivas das salas integradoras, mainstreaming e inclusivas. O sistema de tempo integral restringe as possibilidades de atendimento em programas especializados externos à escola, mas mesmo assim é possível perceber familiares que conseguem adequar a rotina do $\mathrm{CP}$ aos atendimentos oferecidos por estes programas. 


\section{Resultados e discussão}

Considerando a ainda incipiente experiência vivenciada no CP, já é possível trazer algumas reflexões que mostram tanto as potencialidades quanto os desafios ou as limitações que o AEE possui, a partir da organização escolar em tempo integral.

Com relação às potencialidades, verifica-se até o momento que o trabalho de AEE no CP tem dado contribuições significativas para a diversificação das práticas de ensino, bem como tem fornecido elementos para se pensar em estratégias que viabilizem o desenvolvimento dos estudantes PAEE. Com isso, o AEE assume a responsabilidade de se constituir como mais uma possibilidade de promoção do aprendizado a partir das diversas variáveis comportamentais, limitações e competências apresentadas por estes estudantes.

A metodologia do trabalho do AEE, que fundamentalmente acontece com atendimento individualizado na sala de recursos, estrutura-se em quatro momentos, sendo: a) momento de conversa, no qual há questionamentos aos estudantes sobre como estão se sentindo naquele dia, dificuldades escolares, novidades, passeios com as famílias, incômodos e alegrias; b) uso de jogos de mesa e tabuleiro, em geral com objetivo de desenvolver a capacidade de lidar com as frustrações, a competitividade, o raciocínio, a oralidade, conforme a necessidade de cada um; c) registro no Caderno de AEE, que constitui em atividades direcionadas para sanar dificuldades de escrita, coordenação, leitura, interpretação, recorte, colorido, compreensão de conteúdos do currículo; d) atividades com uso do computador, com pesquisas na internet de temas pertinentes, vídeos e páginas educativas, e principalmente a resolução de atividades utilizando o software educacional Educatrix ${ }^{1}$.

Outra experiência vivida que, apesar de não ser tão frequente como poderia, mas que se mostrou muito eficiente, foi o trabalho integrado com o(s) professor(es) regente(s) da(s) turma(s). Ao acompanhar a aula que é dada na turma pelo professor regente, e consequentemente suas práticas pedagógicas e metodologias de ensino, é possível identificar e até mesmo antecipar dificuldades que os estudantes PAEE podem ter, além de perceber como ele interage com o conteúdo, com o professor e com a turma. Assim, o trabalho do AEE torna-se mais eficaz, uma vez que é fundamental haver a intenção de conectar as aulas de AEE com as aulas da turma. Com isso, num segundo momento a aula acontece na sala de recursos, planejada já com foco nas dificuldades do estudante. Esta proximidade provoca maior estímulo à diversificação das práticas pedagógicas, por parte dos professores regentes.

Nesta perspectiva, o foco é voltado ao desenvolvimento da aprendizagem do estudante PAEE, sem que haja desconexão com o que acontece na turma. São definidas metas simples e concretas no início de cada etapa do ano letivo, que são perseguidas no trabalho cotidiano de cada atendimento AEE.

Para promover o desenvolvimento dos estudantes na escola para além da sala de aula, há uma diversificação de práticas pedagógicas combinadas com um trabalho com foco em dificuldades individuais, ao mesmo passo que são propostas integrações cada vez mais profundas do estudante PAEE com a sua turma.

Acrescenta-se também a necessidade de sistematização da evolução da aprendizagem através da Ficha de Acompanhamento do AEE ou do Plano Educacional Individual (PEI), onde são definidas as metas e onde se tem um parâmetro e orientações que norteiam o trabalho do dia a dia (ALKAHTANI; KHEIRALLAH, 2016).

Apesar de não haver estudos sistematizados a respeito do comportamento e receptividade dos estudantes ao AEE no âmbito do CP, é possível perceber a melhora da autoestima e um avanço na construção de repertório próprio na comunicação com seus pares. Ao mesmo tempo, percebe-se que os estudantes se tornam mais seguros, participativos, ativos, enfim, mais felizes e capazes de conviver com seus pares com mais autonomia.

1 Educatrix é um software educativo, desenvolvido pela professora Clenice Griffo, do Centro Pedagógico da UFMG, destinado ao desenvolvimento da aprendizagem em crianças da educação infantil (pré-escola) e do 1ㅇ ao 50 anos do ensino fundamental. 0 programa oferece aulas interativas e interdisciplinares, com caráter complementar aos conteúdos escolares.

Disponível em: www.educatrix.com.br. Acesso em: 11 jan. 2020. 
É importante destacar que uma escola inclusiva promove e fortalece a democracia, pois é a partir dessa realidade que a inclusão ocorre em outros espaços sociais. Em outras palavras, a sociedade é transformada pela influência da escola.

Destaca-se também o alcance de melhores resultados acadêmicos por diversos estudantes PAEE, e o desenvolvimento das habilidades sociais, observadas na escola, com seus familiares e a partir de relatos das famílias em outros ambientes não escolares.

Com relação aos limites e desafios, especialmente por se tratar de um processo ainda incipiente, a inclusão encontra diversas limitações, ocasionadas especialmente pela rigidez do atual sistema educacional. Um dos primeiros passos para diminuir os desafios no processo inclusivo é reconhecer a diversidade que existe em nossa sociedade e utilizar-se dela como um meio de transformação, valorizando cada pessoa pelas qualidades e habilidades que possui. As limitações se atenuam quando a escola está aberta para acolher toda a diversidade.

Há ainda grande necessidade de sensibilização ao tema, na comunidade acadêmica. As ainda restritas ações de inclusão precisam não apenas ocorrer para dentro, mas para além do ambiente escolar. Para isso, importa promover a qualificação docente constantemente. Nesse sentido, a promoção do processo inclusivo de pessoas com deficiência nas escolas e, consequentemente em outros espaços não escolares, deve ser feito não apenas por especialistas, mas por todos os envolvidos, família, equipe pedagógica, comunidade, de forma indiscriminada.

A efetivação da inclusão nas escolas é um longo caminho a ser percorrido. Muitas barreiras ainda precisam ser derrubadas, sejam nos aspectos técnico-estruturais, materiais, governamentais ou humanos. Nesse sentido, os estudantes “típicos” precisam ser preparados e orientados para conviverem com as pessoas com deficiência, daí a importância do envolvimento dos professores em conversar, interagir, informar, e fazer um trabalho conjunto com as famílias e comunidade acadêmica. Em muitos casos, os estudantes não são instruídos em casa, havendo a necessidade de a escola criar projetos informativos para mostrar às crianças e às famílias algumas adaptações que são importantes a determinados estudantes, para que possam participar das aulas diante de suas necessidades especiais. Dessa maneira, as necessidades especiais não serão entendidas como benefícios ou privilégios de que elas as crianças tidas como “típicas” não estão desfrutando, e assim não se sentirão desmotivadas e inferiorizadas, limitando o processo de inclusão. Ademais, o aprimoramento das práticas pedagógicas dos professores traz benefícios para todas as crianças, e não apenas para as crianças PAEE.

Independentemente de a criança possuir ou não alguma deficiência, cada uma delas tem seu próprio ritmo de aprendizado, que deve ser respeitado. As crianças precisam aprender a observar o ritmo de aprendizado diferenciado que existe entre seus pares para que aprendam a respeitar as próprias limitações e as dos outros. Quando as crianças percebem e entendem as limitações dos colegas, tendem a ser solidárias e passam a participar com naturalidade desse processo de inclusão, tornando-o mais simples e leve.

Outros dilemas também podem ser observados, como a transferência de responsabilidades. Ainda é possível observar profissionais da educação que transferem toda a responsabilidade do desempenho dos estudantes PAEE ao profissional de Educação Especial. Com isso, não basta contar apenas com o atendimento colaborativo em sala de aula (co-docência) ou o atendimento itinerante, em sala de recursos, mas deve haver engajamento total de todos os responsáveis, incluindo familiares. Assim, o fato de as escolas de tempo integral não terem contraturno, evoca a necessidade de os profissionais se envolverem ainda mais no processo inclusivo, uma vez que, em diversos casos, a escola é o único espaço onde o estudante PAEE terá os atendimentos que lhe são necessários. Alguns destes principais motivos de envolvimento generalizado residem no fato de os estudantes, numa rotina de uma escola em tempo integral, terem uma quantidade maior de intervalos, tempos de socialização e diversificação de usos dos espaços - como biblioteca, refeitório, playground, enfermaria, dentre outros. A presença de estudantes nos mais diversos espaços da escola, seja em maiores ou menores intervalos de tempo, demandam preparo por parte de todos os servidores diretamente envolvidos com as rotinas escolares, sejam elas pedagógicas ou administrativas, o que demanda treinamento especializado e mesmo individualizado. Acrescenta-se ainda a necessidade 
de viabilização legal da contratação de servidores assistentes de alunos - cargo atualmente disponível para contratação apenas por Institutos Federais (IF) -, que podem dar contribuições decisivas para a adaptação dos estudantes PAEE aos diferentes espaços da escola, além de ser possível a estes profissionais dar outras contribuições que ultrapassam o ofício do professor, como os cuidados cotidianos relacionados especialmente à mobilidade e higiene.

Com relação a alguns familiares, observam-se ingerências no sentido de interferir nas escolhas de quais seriam as aulas mais adequadas a se "perder", para seus filhos serem atendidos pela professora de AEE. Nesse sentido, o ideal é que situações dessa natureza sejam organizadas juntamente com as famílias dos estudantes, para que o processo inclusivo não tenha mais esse dificultador.

Outro aspecto a ser considerado é a necessidade de atenção e ritmos diferenciados, que pode desestimular estudantes "típicos". Uma vez que as turmas regulares cedo ou tarde terão estudantes PAEE, cabe aos profissionais envolvidos no processo educativo o desenvolvimento de estratégias que envolvam todos os estudantes, conforme suas potencialidades.

Por fim, estudos precisam ser desenvolvidos para que o processo de inclusão possa ocorrer também a partir da criança. Em outras palavras, há demanda de estudos para compreensão a respeito da percepção da criança PAEE de como ela vê o AEE, a EE e sua inserção na chamada "sociedade normalizada".

\section{Considerações finais}

A ainda recente experiência do CP como uma escola inclusiva de tempo integral conciona outros tempos de relações entre estudantes, de estudantes com professores, e dos professores com suas práticas e convicções didático-pedagógicas. Estas mudanças de paradigmas já estão provocando novas relações entre os atores envolvidos em sala de aula e as respectivas práticas pedagógicas, antes mesmo de os professores se adaptarem adequadamente à geração nativa digital.

As salas de aula inclusivas, independentemente da modalidade de inclusão, trazem novas e significativas oportunidades de socialização, pois é necessário haver mudança de princípios, valores e convicções além da efetivação da valorização da diversidade em todas as suas esferas (física, mental, de gênero, étnica, etc.).

Por fim, mas não menos importante, vale reafirmar a necessidade de posicionamento do Governo Federal frente às demandas que se apresentam. Este posicionamento, em princípio, em duas frentes: primeiramente, deve-se viabilizar todas as condições necessárias para um trabalho inclusivo eficaz. Dentre essas ações, destacam-se a contratação de profissionais conforme demandas de cada CAp, a aquisição de materiais didático-pedagógicos que contribuam para a aceleração e consolidação do aprendizado, além do investimento em estrutura física e mobilidade. Em segundo, especificamente para escolas de tempo integral, tanto o $\mathrm{CP}$ quanto outras que porventura surjam, as leis precisam considerar os tempos, espaços, ritmos e rotinas de cada uma delas, uma vez que a lógica das leis em vigor consideram apenas as escolas que possuem estudantes em dois turnos.

Nesse sentido, novos estudos são necessários, para que o processo de inclusão em escolas de tempo integral possa ocorrer de maneira plena e irrestrita.

\section{Referências}

ALKAHTANI, Mohammed Ali; KHEIRALLAH, Sahar Abdelfattah. Background of Individual Education Plans (IEPs) Policy in Some Countries: a review. Journal of Education and Practice, Hong Kong, v. 7, n. 24, p. 15-26, 2016.

BRASIL. Diretrizes Operacionais da Educação Especial para o Atendimento Educacional Especializado na Educação Básica. Brasília, DF: MEC: SEESP, 2008.

BRASIL. Decreto n 7.611, de 17 de novembro de 2011. Dispõe sobre a educação especial, o atendimento educacional especializado e dá outras providências. Diário Oficial da União: seção 1, Brasília, DF, p. 12, 18 nov. 2011. 
BRASIL. Lei no 13.005, de 25 de junho de 2014. Aprova o Plano Nacional de Educação - PNE e dá outras providências. Diário Oficial da União: seção 1, Brasília, DF, p. 1, 26 jun. 2014.

DAVID, Lilian; CAPELLINI, Vera Lúcia Messias Fialho. O ensino colaborativo como facilitador da inclusão da criança com deficiência na educação infantil. Nuances: Estudos sobre Educação, Presidente Prudente, v. 25, n. 2, p. 189-209, maio/ago. 2014

DE BOER, Anke; PIJL, Sip Jan; MINNAERT, Alexander. Regular primary school teachers' attitudes towards inclusive education: a review of the literature. International Journal of Inclusive Education, United Kingdom, v. 15, n. 3, p. 331-353, 2011.

DEMO, Pedro. Pesquisa participante: mito e realidade. Brasília, DF: Inep, 1982.

HORNBY, Garry. Inclusive special education: development of a new theory for the education of children with special educational needs and disabilities. British Journal of Special Education, United Kingdom, v. 42, n. 3, p. 234-256, 2015.

ORGANIZAÇÃO DAS NAÇÕES UNIDAS PARA A EDUCAÇÃO, A CIÊNCIA E A CULTURA (UNESCO). Declaração Mundial de Educação para Todos: satisfação das necessidades básicas de aprendizagem, Jomtien, 1990. Brasília, DF: UNESCO, 1998.

Data de submissão: 28/04/2020

Data de aceite: $23 / 06 / 2020$ 